\title{
Outcomes of venoarterial extracorporeal membrane oxygenation for refractory cardiogenic shock: systematic review and meta- analysis
}

\author{
Ashley R. Wilson-Smith ${ }^{1,2}$, Yulia Bogdanova ${ }^{2}$, Stephanie Roydhouse ${ }^{2}$, Kevin Phan ${ }^{1}$, David H. Tian ${ }^{1,3}$, \\ Tristan D. Yan ${ }^{1,4}$, Antonio Loforte ${ }^{5}$ \\ ${ }^{1}$ The Collaborative Research Group (CORE), Macquarie University, Sydney, Australia; ${ }^{2}$ The University of New South Wales, Faculty of Medicine, \\ Sydney, Australia; ${ }^{3}$ Royal North Shore Hospital, Sydney, Australia; ${ }^{4}$ Department of Cardiothoracic Surgery, Royal Prince Alfred Hospital (RPA), \\ Camperdown, Australia; ${ }^{5}$ Department of Cardiovascular Surgery and Transplantation, St. Orsola-Malpighi Hospital, University of Bologna, Bologna, \\ Italy \\ Correspondence to: Ashley R. Wilson-Smith. The Collaborative Research Group (CORE), Macquarie University, Sydney, Australia. \\ Email: wilsonsmithash597@gmail.com.
}

\begin{abstract}
Background: Despite advances in management techniques and medical therapy, refractory cardiogenic shock remains a life-threatening condition with high mortality rates. The present systematic review and meta-analysis aims to explore the outcomes associated with venoarterial extracorporeal membrane oxygenation (VA-ECMO) use in the setting of refractory cardiogenic shock, stratified per survivorship.

Methods: A literature search was performed using three electronic databases from the date of their inception up to June 2018. The literature search and subsequent data extraction were performed by two independent reviewers. Digitized survival data were extracted from Kaplan-Meier curves in order to recreate the original patient data using an iterative algorithm and were subsequently aggregated for analysis.

Results: Fifty-two studies were included, with 44 undergoing quantitative analysis. A total of 17,515 patients were identified, with a mean age of 58.4 \pm 9.4 years and a mean duration of ECMO support of $5.1 \pm 2.6$ days; $68.7 \%$ of the patients were male. Aggregated survival rates at 1, 2, 3 and 5 years were $36.7 \%$, $34.8 \%, 33.8 \%$ and $29.9 \%$, respectively.

Conclusions: The present systematic review illustrates the expected survival results for VA-ECMO in the intermediate- to long-term. Extended follow-up and standardized reporting measures are urgently needed in order to carry out more definitive subgroup analyses.
\end{abstract}

Keywords: Extracorporeal membrane oxygenation (ECMO); ECLS; refractory cardiogenic shock

Submitted Oct 02, 2018. Accepted for publication Nov 20, 2018.

doi: $10.21037 /$ acs.2018.11.09

View this article at: http://dx.doi.org/10.21037/acs.2018.11.09

\section{Introduction}

Despite advances in management techniques and medical therapy, refractory cardiogenic shock remains a lifethreatening condition with high mortality rates (1). Both low cardiac output and poor tissue perfusion characterize cardiogenic shock and hence a great deal of emphasis is placed on the use of inotropic and vasopressor agents, mechanical assistance and fluid maintenance to support cardiac function (2). Mechanical support for the management of cardiogenic shock was first assessed in animal trials as early as the 1930s, with extension to human trials in the late 1960s in the setting of infants with respiratory sepsis (3-5). The efficacy of extracorporeal membrane oxygenation (ECMO) as a tool for the management of shock syndromes was established in the 1970s, but it was introduced slowly to mainstream intensive care medicine after a series of setbacks (6-8). More recently, ECMO has been widely employed for a range of cardiovascular and respiratory conditions 
resulting in cardiogenic shock that are refractory to medical management, namely, acute myocardial infarction (AMI), postcardiotomy-related shock (PCT), graft failure in heart transplant (GFIHT) and acute decompensated heart failure (ADHF), particularly in the wake of successful trials $(9,10)$. The present systematic review and meta-analysis aims to explore the current outcomes associated with venoarterialECMO (VA-ECMO) use in the setting of refractory cardiogenic shock, stratified per survivorship, with a discussion on cannulation method and presenting pathology.

\section{Methods}

\section{Literature search strategy}

This review was performed in accordance with PRISMA recommendations and guidance (11). Electronic searches were performed on PubMed, Scopus and Medline from dates of database inception to June 2018, using ("venoarterial" OR "veno-arterial") AND ("extracorporeal membrane oxygenation" OR "ECMO" OR "extracorporeal life support" OR "ECLS" OR "VA ECMO" OR "VAECMO" OR "V-A-ECMO") AND (“cardiogenic shock"), as either keywords or MeSH headings. After removal of duplicate records, studies were reviewed according to the inclusion and exclusion criteria detailed below by two independent authors. A PRISMA diagram of the search strategy is presented in Figure S1. Additional references for discussion were included via a reference list search or via targeted database searches.

\section{Inclusion and exclusion criteria}

Studies were included if they had at least 10 patients in their cohorts and where VA-ECMO had been used in supporting patients with refractory cardiogenic shock. Non-English studies, review articles, conference and paper abstracts, editorials, letters and opinions were all excluded. Studies were also excluded if they did not present baseline patient characteristics, or the focus of the study was in a cohort composed of patients $<18$ years.

\section{Quality assessment of included studies}

An appraisal schema based on the Canadian National Institute of Health Economics' (IHE) Quality Assessment Tool (i.e., the modified Delphi technique) for Case Series Studies was employed to evaluate all included studies. The evaluation was carried out by two independent reviewers. Studies were categorized based on the following domains: clarity of study objective, adequate description of the study population, description of the intervention, adequate reporting of outcome measures and appropriate reporting of results/conclusions. Quality findings are listed in Table S1.

\section{Statistical analysis}

Baseline patient characteristics, risk factors, operative details and outcomes of interest were extracted by two independent researchers. Kaplan-Meier curves were digitized where presented and an algorithmic computational tool was utilized, as outlined by Guyot and colleagues, to derive individual patient data (12). Censoring was assumed to be constant, unless the particular curve had a long follow-up of only minimal patients-in which case, censoring was manually entered. Death events and censoring data were compiled for the entire patient cohort and overall survival curves were produced as per the Kaplan-Meier method using IBM SPSS Statistics 25 (IBM Corp. Released 2017; IBM SPSS Statistics for Macintosh, Version 25.0. Armonk, NY, USA: IBM Corp) after being digitized. Studies that included high-resolution Kaplan-Meier curves, alongside numbers at risk, where included in the aggregation. Where studies had broken their cohorts into subgroups, individual KM curves were generated for these first and then merged, prior to being included in the whole cohort analysis. Studies that failed to report numbers at risk, or had data points obscured by censoring brackets, were excluded. These measures were applied in order to reduce the heterogeneity of the population and increase the validity of the findings. Data collection and meta-analysis of study characteristics were carried out using IBM SPSS Statistics 25 and Review Manager 5 (version 5.3, Cochrane Collaboration, Oxford, United Kingdom).

\section{Results}

A total of 789 references were identified in the search. After applying the inclusion and exclusion criteria, 52 studies were included for qualitative analysis, of which 44 went on to quantitative analysis. Of these 44 quantitative studies, 25 were of medium quality and 19 were of high quality, as defined by the IHE assessment tool (see Table S1). Of the studies included for quantitative analysis, 20 of the studies were from European centers, 14 were Asian/Australasian and 10 were from the United States, with recruitment 


\begin{tabular}{|c|c|}
\hline Characteristics & Outcome \\
\hline Total patients & 17,515 \\
\hline Males (n, \%) & $12,036(68.7 \%)$ \\
\hline Age, mean \pm SD (years) & $58.4 \pm 9.4$ \\
\hline $\mathrm{BMI}$, mean $\pm \mathrm{SD}\left(\mathrm{kg} / \mathrm{m}^{2}\right)$ & $25.0 \pm 4.9$ \\
\hline Body surface area, mean \pm SD $\left(\mathrm{m}^{2}\right)$ & $1.9 \pm 0.2$ \\
\hline \multicolumn{2}{|l|}{ Etiology/cause of shock (where delineated) (n) } \\
\hline Postcardiotomy & 613 \\
\hline Acute myocardial infarction & 993 \\
\hline Graft failure in transplant & 466 \\
\hline Acute decompensated heart failure & 213 \\
\hline Undefined/other refractory cardiogenic shock & 15,230 \\
\hline \multicolumn{2}{|l|}{ Cannulation method (n) } \\
\hline Central & 646 \\
\hline Peripheral & 2,088 \\
\hline Undefined & 14,781 \\
\hline Preoperative LVEF, mean \pm SD (\%) & $29.4 \pm 7.3$ \\
\hline CPB duration, mean \pm SD (min) & $206.0 \pm 39.5$ \\
\hline CPR (\%) & $75.5 \%$ \\
\hline Time on ECMO, mean (days) & $5.1 \pm 2.6$ \\
\hline IABP (\%) & $53.4 \%$ \\
\hline Lactate, mean $\pm \mathrm{SD}(\mathrm{mmol} / \mathrm{L})$ & $12.0 \pm 5.0$ \\
\hline Creatinine, mean $\pm \mathrm{SD}(\mathrm{mg} / \mathrm{dL})$ & $1.5 \pm 0.7$ \\
\hline
\end{tabular}

The results presented are in weighted means, inter-quartile ranges, or $n / \%, \pm$ standard deviation. Survival was considered to be at primary discharge. Characteristics were combined where presented. CPB, cardiopulmonary bypass; CPR, cardiopulmonary resuscitation; ECMO, extracorporeal membrane oxygenation; IABP, intra-aortic balloon pump.

periods between 1986 and 2016. A total of 17,515 patients were identified as having been placed on VA-ECMO for the management of refractory cardiogenic shock from 1996 to 2018. Only 2,734 patients (15.6\%) were specified as having either undertaken central or peripheral ECMO, with the rest of the cohort remaining undefined. Full study characteristics are reported in Table $S 2$.

The mean age of the population was $58.4 \pm 9.4$ years and the mean time spent on ECMO support was 5.1 \pm 2.6 days. Within this population, 613 were treated for PCT,
993 for AMI, 466 for graft failure and 213 for ADHF. A total of 15,230 subjects were managed for other conditions resulting in refractory cardiogenic shock or were undefined. Body mass index (BMI) and body surface area (BSA) had mean values of $25.0 \pm 4.9 \mathrm{~kg} / \mathrm{m}^{2}$ and $1.9 \pm 0.2 \mathrm{~m}^{2}$, respectively. Mean preoperative left ventricular ejection fraction (LVEF) was found to be $29.4 \% \pm 7.3 \%$. Cardiopulmonary resuscitation (CPR) and intra-aortic balloon pump (IABP) use were reported in $31.9 \%$ and $48.9 \%$ of studies, yielding totals of 1,081 and 3,989 patients, respectively. They were administered in $75.5 \%$ and in $53.4 \%$ of subjects, when weighted. Mean CPB time was found to be $206.0 \pm 39.5$ minutes, where reported. Baseline serum lactate and creatinine were $12.0 \pm 5.0 \mathrm{mmol} / \mathrm{L}$ and $1.5 \pm 0.7 \mathrm{mg} / \mathrm{dL}$ and were reported in $47.7 \%(21 / 44)$ and $31.8 \%$ of studies (14/44), respectively (Table 1).

\section{Survivors $v s$. non-survivors (Table 2)}

Survival-to-discharge was found to be $43.0 \%$ in a total cohort of 5,292 patients. Of these 5,292, 3,575 patients were male. The mean age of survivors versus non-survivors was $55.1 \pm 13.2$ and $56.1 \pm 12.8$ years and the mean duration of ECMO support was $4.0 \pm 2.1$ and $3.8 \pm 3.5$ days, respectively. Mean CPB time was found to be $192.6 \pm 110.2$ and $216.6 \pm 99.8 \mathrm{~min}$. CPR was carried out in $31.2 \%$ of survivors versus $58.3 \%$ in non-survivors. Lactate and creatinine levels were found to be slightly higher in non-survivors than in survivors. The rates of acute respiratory distress syndrome (ARDS), acute kidney injury (AKI), liver dysfunction, bleeding and CVA/neurological dysfunction were all higher in non-survivors. Infection was found to be higher in survivors. Forest plot analysis for in-hospital complications are reported in Figure $S 2$.

\section{Whole cohort: long-term survival}

Aggregated survival rates at 1, 2, 3, 4 and 5 years were $36.7 \%, 34.8 \%, 33.8 \%, 31.7 \%$ and $29.9 \%$, respectively. The overall cohort data is presented in Figure 1. The follow-up period was between 2000 and 2015.

\section{Discussion}

\section{Contemporary outcomes of VA-ECMO administration}

Since their inception, extracorporeal life support systems have seen tremendous modifications throughout several, 


\begin{tabular}{|c|c|c|c|}
\hline Characteristics of cohort $(n=5,292)$ & Survivors $(n=2,278)$ & Non-survivors $(n=3,014)$ & $\mathrm{P}$ value (MD/OR) \\
\hline Males (n, \%) & $1,545(67.8 \%)$ & $2,030(67.4 \%)$ & $0.72(1.01 ; 95 \% \mathrm{Cl}, 0.97$ to 1.05$)$ \\
\hline Age, mean \pm SD (years) & $55.1 \pm 13.2$ & $56.1 \pm 12.8$ & $0.006(-1.00 ; 95 \% \mathrm{Cl},-1.71$ to -0.29$)$ \\
\hline Time on ECMO, mean \pm SD (days) & $4.0 \pm 2.1$ & $3.8 \pm 3.5$ & $0.010(0.20 ; 95 \% \mathrm{Cl}, 0.05$ to 0.35$)$ \\
\hline CPR (\%) & 31.2 & 58.3 & $<0.001(0.33 ; 95 \% \mathrm{Cl}, 0.18$ to 0.58$)$ \\
\hline Lactate, mean $\pm \mathrm{SD}(\mathrm{mmol} / \mathrm{L})^{*}$ & $14.0 \pm 13.3$ & $19.2 \pm 15.2$ & $<0.001(-5.2095 \% \mathrm{Cl},-5.97$ to -4.43$)$ \\
\hline Creatinine, median (range) $(\mathrm{mg} / \mathrm{dL})^{*}$ & $1.3(1.1-1.7)$ & $1.6(1.2-2.3)$ & \\
\hline \multicolumn{4}{|l|}{ In-hospital complications (\%) } \\
\hline Liver dysfunction* & 13.9 & 29.8 & $0.007(0.38 ; 95 \% \mathrm{Cl}, 0.19$ to 0.77$)$ \\
\hline Bleeding* & 9.1 & 13.5 & $0.27(0.61 ; 95 \% \mathrm{Cl}, 0.25$ to 1.48$)$ \\
\hline CVA/neurological dysfunction & 12.5 & 22.5 & $0.07(0.50 ; 95 \% \mathrm{Cl}, 0.24$ to 1.05$)$ \\
\hline Infection & 24.6 & 11.5 & $0.02(2.44 ; 95 \% \mathrm{Cl}, 1.15$ to 5.20$)$ \\
\hline \multicolumn{4}{|c|}{$\begin{array}{l}\text { The results presented are in means, inter-quartile ranges, or } \mathrm{n} / \% \text {. Survival was considered to be those alive of the total cohort at primary } \\
\text { discharge. *, lactate and creatinine levels were taken as soon as ECMO started (i.e., at baseline), or when first convenient. Bleeding was } \\
\text { defined as any incident where unexpected blood loss occurred. Liver dysfunction was defined as any change from normal functioning, } \\
\text { including shock liver and generalized inflammation. Significance is set at a P value of } 0.05 \text {. BMI, body mass index; LVEF, left ventricular } \\
\text { ejection fraction; ECMO, extracorporeal membrane oxygenation; CPR, cardiopulmonary resuscitation; ARDS, acute respiratory distress } \\
\text { syndrome; AKI, acute kidney injury requiring renal replacement therapy; CVA, cerebrovascular accident; MD, mean difference; OR, odds } \\
\text { ratio; } \mathrm{Cl} \text {, confidence interval. }\end{array}$} \\
\hline
\end{tabular}

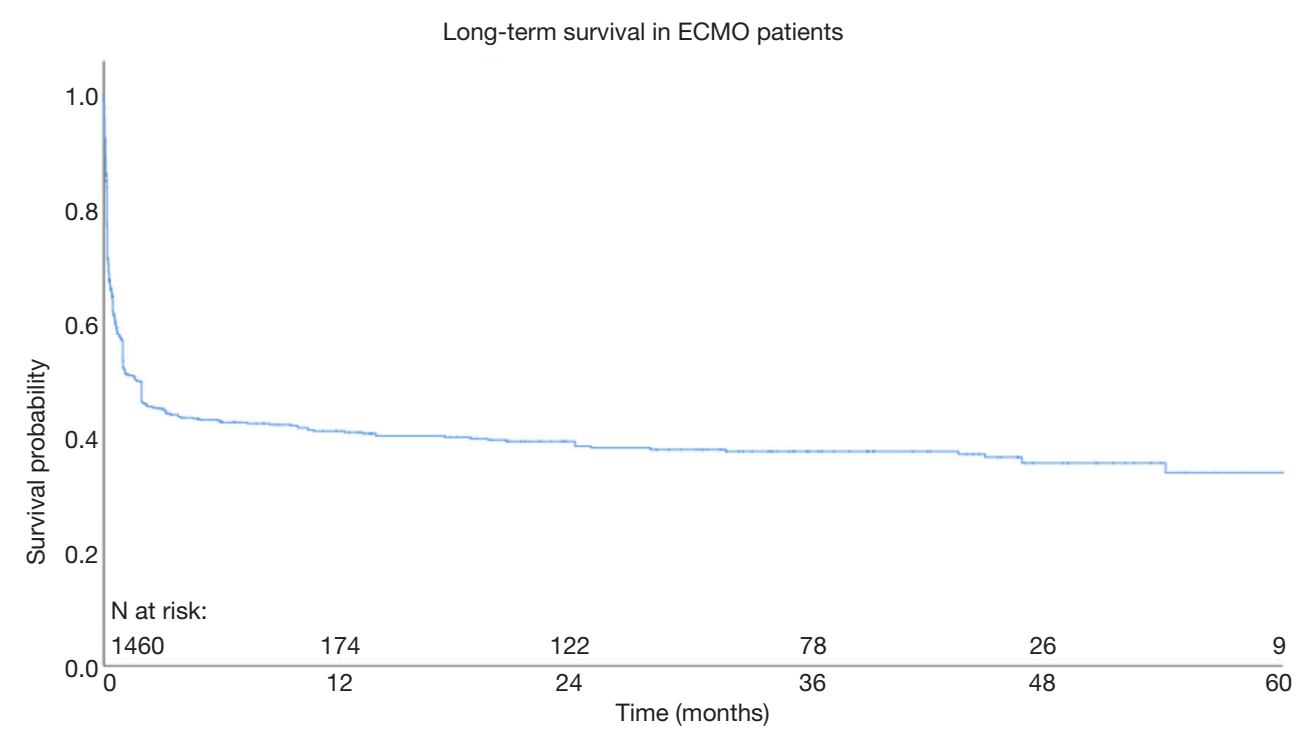

Figure 1 Aggregated survival for the entire cohort using Kaplan-Meier estimation. 
rapid eras of development. With applications in pediatric heart and lung disease and in adults suffering from shock syndromes, ECLS has always been associated with highrisk cohorts. The high-risk nature of the patient population undergoing VA-ECMO is reflected by the findings of this analysis, with an overall survival-to-discharge rate of $43.0 \%$. This is in line with the data presented in the literature (13-16). Intermediate-term survival appears to be consistent, with aggregated survival rates at 1, 2, 3 and 4 years at $36.7 \%$, $34.8 \%, 33.8 \%, 31.7 \%$ and $29.9 \%$, respectively.

\section{Significant prognostic factors: survivors $v s$. non- survivors}

In an effort to increase the validity and reliability of this analysis, whilst minimizing the heterogeneity of an already diverse population, only the studies that had delineated outcomes of their survivor $v s$. non-survivor cohorts were included for subgroup analysis. In the contemporary setting, a number of factors have been found to be predictive of increased mortality on VA-ECMO. Time elapsed prior to VA-ECMO administration has been found to be shorter in survivors than in non-survivors $(13,17)$. Out-of-hospital cardiac arrests are associated with poorer outcomes, likely due to the pre-existence of comorbidities and poor return of spontaneous circulation after life support administration (14). Non-survivors typically have increased uptake of renal replacement therapies, which is reflected by the present analysis with higher rates of AKI noted in this cohort (18). CEF scores, SOFA scores, APACHE II scores, SAPS II scores and troponin levels on day 1 of ECMO administration have been correlated with inhospital mortality, with a high Youden index and prediction of correctness illustrated, particularly by $\operatorname{ACEF}(19,20)$. Non-survivors have also been found to have higher levels of CK-MB than survivors, reflecting a greater degree of myocardial injury and irreversibility (18). ECMO duration is not typically different between survivor and non-survivor cohorts $(21,22)$. It is of note that survivors were more than twice as likely to have infections whilst in hospital. It is possible that this is as a result of the heterogeneity of the infection reporting within ECMO studies and from variance in the amount of time patients were in hospital; survivors would be more likely to survive the immediate postoperative period to discharge and hence be exposed to infection risks for an increased amount of time, whereas non-survivors would die prior. Forest plot analysis of a small subset of studies with clearly defined outcome data between survivors and non-survivors failed to clarify this finding, with survivors being less likely to have infections, but the result not being significant (see Figure S2). Specific delineations between infection types (e.g., surgical site infection, line infection, etc.) in future studies would be helpful in elucidating this further.

Cardiac arrest prior to VA-ECMO administration, lack of IABP use, older age, low or high BMI, high serum lactate levels and clinician unfamiliarity with ECMO systems/ poor interdisciplinary cohesion have been highlighted as predictors of in-hospital mortality $(17,23,24)$. High serum lactate, in particular, has been a consistently reported variable in the literature, with ranges of $5-20 \mathrm{mmol} / \mathrm{L}$ being shown to be predictive of mortality. Indeed, the present analysis affirms this relationship. It has been suggested that providing early support prior to reaching precarious levels could improve outcomes $(17,18)$. Hospital volume has not been found to be predictive of poorer outcomes (23). Favourable outcomes with the use of a left ventricular assist device have also been illustrated, as temporary mechanical support allows for more efficacious stabilization of the patient in emergency settings. Most often, the reported causes of death whilst on ECMO are multi-system organ failure (MOF), likely stemming from infection and/or poor perfusion, and lack of neurological recovery (25).

\section{Postcardiotomy, AMI, graft failure, ADHF}

The initiation of VA-ECMO in postcardiotomy subjects has been found to improve survival and is associated more often with central cannulation, as the chest is already open and easy conversion from CPR to ECMO can take place $(26,27)$. As the vast majority of ECMO cohorts are composed of subjects presenting with cardiac arrest, AMIrelated outcomes are closely tied to the aforementioned predictors of survival and hence will be improved as treatment strategies are refined. Graft failure and ADHF are two etiologies that require far more attention, with little data being presented on their specific outcomes outside of select institutions; Loforte and colleagues present an ideal framework for the presentation of outcomes in this area (9).

\section{Central vs. peripheral cannulation}

Whether to cannulate centrally versus peripherally remains an ongoing point of contention. As mentioned previously, central cannulation is ideal in the setting of postcardiotomy shock. Higher flows can also be tolerated, with better 
whole-body perfusion as a result. Central cannulation and right axillary cannulation are more physiologically sound than retrograde cannulation, providing more natural and effective perfusion to the whole body (18). Central cannulation does run the risk of mediastinal bleeding, often requiring exploration to be resolved (28). In contrast, peripheral cannulation has been shown to cause retrograde perfusion and conflicting flow, limiting tissue recovery (26).

Whilst peripheral cannulation confers better lower body perfusion, poor upper body, coronary and cerebral perfusion calls into question its efficacy in severely hemodynamically unstable subjects; there is a need for data on temporary and permanent neurological deficits secondary to peripheral VA-ECMO administration, as at present, very minimal data exist. Limb ischemia and nerve injury-in the setting of axillary cannulation-are also concerns. Infection risk is notably lowered in peripheral administration and is often preferred to central cannulation given the necessity of anticoagulation therapy (29). Weaning from mechanical ventilation is typically also easier and safer in the peripheral setting, with recommendations being made in recent studies that peripheral cannulation should be considered first, except in the instance where the patient has small femoral vessels, or where they are suffering from PCT (30).

\section{Long-term survival}

Limited data exist on the long-term survival outcomes of subjects who underwent VA-ECMO for the management of refractory cardiogenic shock. This study presents an aggregation of the existing survival data, drawn from studies that carried out their own survival analysis (see Figure 1). From the analyses, it appears that survival is relatively consistent in the first five years following VAECMO (36.7\% to $29.9 \%$ ). Additional subgroup analysis on long-term survival was not able to be carried out, as too few studies presented KM curves stratified based on etiology.

\section{Limitations}

There are a number of limitations which constrain the present analysis. First and foremost, the reporting style for the studies examining whole-cohort outcomes are disparate, with clinical characteristics varying substantially and with a number of critical characteristics not being reported at all (e.g., $\mathrm{CPB} / \mathrm{CPR}$ administration and duration, complications, etc.). This is despite the overwhelming majority of the included studies being published within the last decade. This restricts meaningful, detailed subgroup analysis for a number of clinically relevant covariates. This was largely circumvented by focusing on the most commonly reported variables (e.g., serum lactate, creatinine, etc.). The baseline characteristics of the cohort presented is therefore not exhaustive, with room for additional analysis as more studies are published; without standardization of reporting methods for core clinical characteristics, increased study volume is the only pathway to increased validity. With a few notable exceptions, a substantial proportion of the studies included in the quantitative analysis did not report survival outcomes stratified by etiology/indication for ECMO. Tsai and colleagues present an ideal framework for the presentation of survival data in the contemporary setting (19). Additionally, long-term survival analysis could also be benefited by extended follow-up times, although the reporting rate of survival analysis was acceptable, with $56.8 \%$ of studies (25/44) presenting Kaplan-Meier curves.

A number of the highly weighted studies included in the analysis were unable to report cannulation method as their retrospective data were drawn from large, low-resolution registries (i.e., those with limited operative data), which limits the reliability of the subgroup analysis. Retrospective study also introduces the risk of publication bias, which can be reduced by having clear survivor $v s$. non-survivor analyses. Of the total cohort of 17,515 patients, only 2,734 $(15.6 \%)$ detailed the cannulation method. The indication for ECMO was also reported with a fair degree of variability and instead, a broader definition of refractory cardiogenic shock, including pathologies other than those of interest, was often used. Few studies broke their patient cohorts down into age groups, although all of patients within the overall cohort were adults and non-elderly.

\section{Conclusions}

The findings of this analysis are consistent with common clinical experiences regarding ECMO administration. Overall, ECMO studies tend to suffer from great heterogeneity, with a large number of patients presenting for a variety of conditions that place them at high risk of mortality. This high-risk nature is reflected by the aggregated survival analyses. More thorough and consistent reporting is urgently required in order to overcome this issue. 


\section{Acknowledgements}

None.

\section{Footnote}

Conflicts of Interest: The authors have no conflicts of interest to declare.

\section{References}

1. Napp LC, Kühn C, Bauersachs J. ECMO in cardiac arrest and cardiogenic shock. Herz 2017;42:27-44.

2. Brissaud O, Botte A, Cambonie G, et al. Experts' recommendations for the management of cardiogenic shock in children. Ann Intensive Care 2016;6:14.

3. Dorson W Jr, Baker E, Cohen ML, et al. A perfusion system for infants. Trans Am Soc Artif Intern Organs 1969;15:155-60.

4. Kennedy JH. The role of assisted circulation in cardiac resuscitation. JAMA 1966;197:615-8.

5. Makdisi G, Wang I. Extra Corporeal Membrane Oxygenation (ECMO) review of a lifesaving technology. J Thorac Dis 2015;7:E166-76.

6. Morris AH, Wallace CJ, Menlove RL, et al. Randomized clinical trial of pressure-controlled inverse ratio ventilation and extracorporeal $\mathrm{CO} 2$ removal for adult respiratory distress syndrome. Am J Respir Crit Care Med 1994;149:295-305.

7. Hill JD, O'Brien TG, Murray JJ, et al. Prolonged extracorporeal oxygenation for acute post-traumatic respiratory failure (shock-lung syndrome). Use of the Bramson membrane lung. N Engl J Med 1972;286:629-34.

8. Gibbon JH Jr. Artificial maintenance of circulation during experimental occlusion of pulmonary artery. Arch Surg 1937;34:1105-31.

9. Loforte A, Marinelli G, Musumeci F, et al. Extracorporeal membrane oxygenation support in refractory cardiogenic shock: treatment strategies and analysis of risk factors. Artif Organs 2014;38:E129-41.

10. Peek GJ, Mugford M, Tiruvoipati R, et al. Efficacy and economic assessment of conventional ventilatory support versus extracorporeal membrane oxygenation for severe adult respiratory failure (CESAR): a multicentre randomised controlled trial. Lancet 2009;374:1351-63.

11. Liberati A, Altman DG, Tetzlaff J, et al. The PRISMA statement for reporting systematic reviews and metaanalyses of studies that evaluate healthcare interventions: explanation and elaboration. BMJ 2009;339:b2700.

12. Guyot P, Ades AE, Ouwens MJNM, et al. Enhanced secondary analysis of survival data: reconstructing the data from published Kaplan-Meier survival curves. BMC Med Res Methodol 2012;12:9.

13. Schmidt M, Burrell A, Roberts L, et al. Predicting survival after ECMO for refractory cardiogenic shock: the survival after veno-arterial-ECMO (SAVE)-score. Eur Heart J 2015;36:2246-56.

14. Sharma AS, Weerwind PW, Ganushchak YM, et al. Towards a proactive therapy utilizing the modern spectrum of extracorporeal life support: a single-centre experience. Perfusion 2015;30:113-8.

15. Muller G, Flecher E, Lebreton G, et al. The ENCOURAGE mortality risk score and analysis of longterm outcomes after VA-ECMO for acute myocardial infarction with cardiogenic shock. Intensive Care Med 2016;42:370-8.

16. Schopka S, Philipp A, Hilker M, et al. Clinical course and long-term outcome following venoarterial extracorporeal life support-facilitated interhospital transfer of patients with circulatory failure. Resuscitation 2015;93:53-7.

17. Wang JG, Han J, Jia YX, et al. Outcome of veno-arterial extracorporeal membrane oxygenation for patients undergoing valvular surgery. PLoS One 2013;8:e63924.

18. Zhong $Z$, Jiang $C$, Yang $F$, et al. Veno-Arterial Extracorporeal Membrane Oxygenation Support in Patients Undergoing Aortic Surgery. Artif Organs 2017;41:1113-20.

19. Tsai TY, Tsai FC, Fan PC, et al. Application of the Age, Creatinine, and Left Ventricular Ejection Fraction Score for Patients on Extracorporeal Membrane Oxygenation. Artif Organs 2017;41:146-52.

20. Yeh TC, Chang HH, Ger LP, et al. Clinical risk factors of extracorporeal membrane oxygenation support in older adults. PLoS One 2018;13:e0195445.

21. Saxena P, Neal J, Joyce LD, et al. Extracorporeal Membrane Oxygenation Support in Postcardiotomy Elderly Patients: The Mayo Clinic Experience. Ann Thorac Surg 2015;99:2053-60.

22. Loforte A, Montalto A, Ranocchi F, et al. Peripheral extracorporeal membrane oxygenation system as salvage treatment of patients with refractory cardiogenic shock: preliminary outcome evaluation. Artif Organs 2012;36:E53-61.

23. Aso S, Matsui H, Fushimi K, et al. In-hospital mortality and successful weaning from venoarterial extracorporeal membrane oxygenation: analysis of 5,263 patients using a 
national inpatient database in Japan. Crit Care 2016;20:80.

24. Aubin H, Petrov G, Dalyanoglu H, et al. Four-year experience of providing mobile extracorporeal life support to out-of-center patients within a suprainstitutional network-Outcome of 160 consecutively treated patients. Resuscitation 2017;121:151-7.

25. Takayama H, Truby L, Koekort M, et al. Clinical outcome of mechanical circulatory support for refractory cardiogenic shock in the current era. J Heart Lung Transplant 2013;32:106-11.

26. Liden H, Wiklund L, Haraldsson A, et al. Temporary circulatory support with extra corporeal membrane oxygenation in adults with refractory cardiogenic shock. Scand Cardiovasc J 2009;43:226-32.

27. Muehrcke DD, McCarthy PM, Stewart RW, et al. Extracorporeal membrane oxygenation for postcardiotomy cardiogenic shock. Ann Thorac Surg 1996;61:684-91.

28. Ranney DN, Benrashid E, Meza JM, et al. Central Cannulation as a Viable Alternative to Peripheral Cannulation in Extracorporeal Membrane Oxygenation. Semin Thorac Cardiovasc Surg 2017;29:188-95.

29. Musial R, Moncznik P, Smialek P, et al. Veno-arterial extracorporeal membrane oxygenation for shortterm mechanical circulation support in adults with cardiogenic shock: a single centre experience. Kardiol Pol 2016;74:1477-84.

30. Russo CF, Cannata A, Lanfranconi M, et al. Venoarterial extracorporeal membrane oxygenation using Levitronix centrifugal pump as bridge to decision for refractory cardiogenic shock. J Thorac Cardiovasc Surg 2010;140:1416-21.
Cite this article as: Wilson-Smith AR, Bogdanova Y, Roydhouse S, Phan K, Tian DH, Yan TD, Loforte A. Outcomes of venoarterial extracorporeal membrane oxygenation for refractory cardiogenic shock: systematic review and metaanalysis. Ann Cardiothorac Surg 2019;8(1):1-8. doi: 10.21037/ acs.2018.11.09 


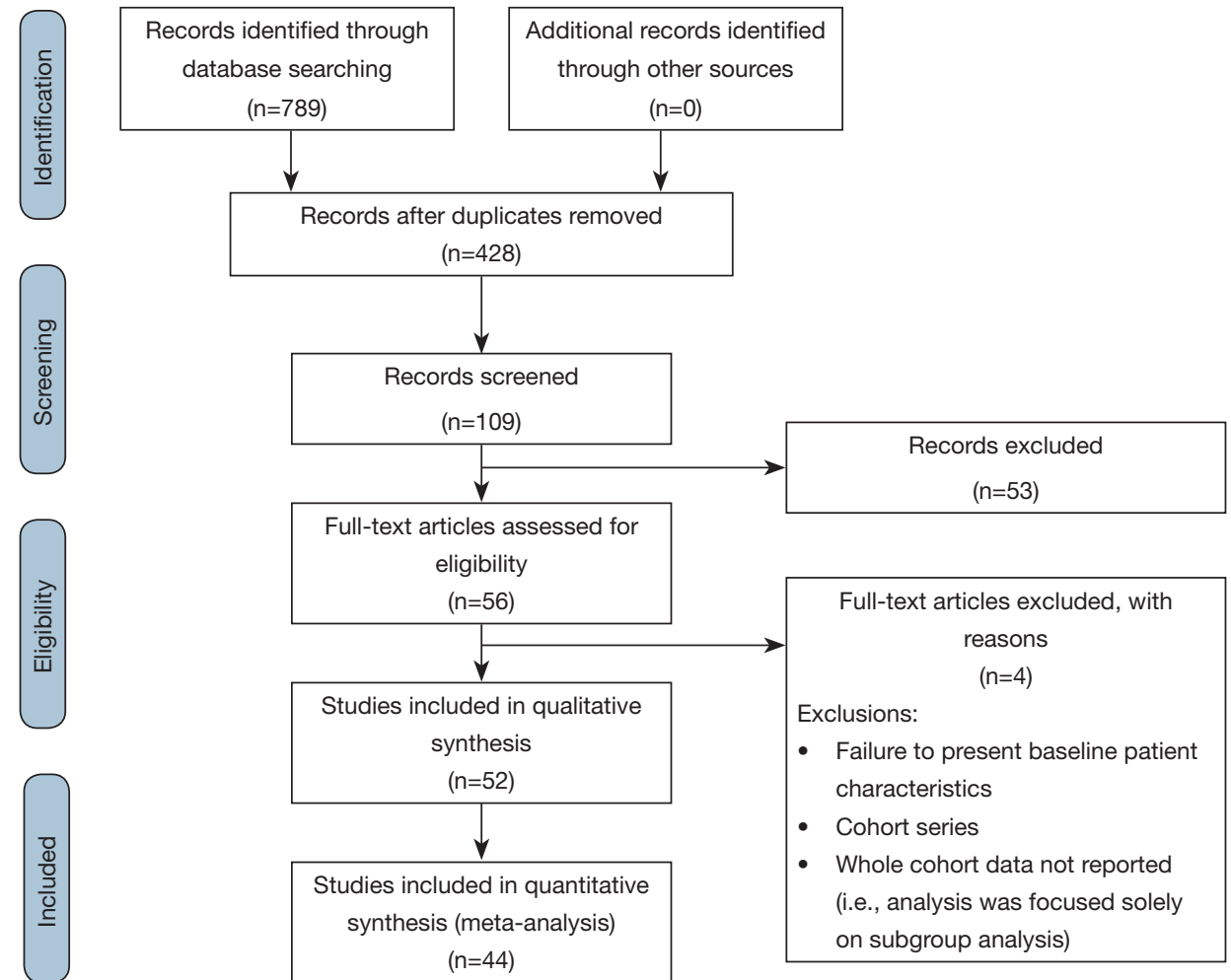

Figure S1 PRISMA flow chart detailing the literature search process for contemporary VA-ECMO outcomes in the setting of cardiogenic shock. ECMO, extracorporeal membrane oxygenation. 


\begin{tabular}{|c|c|c|c|c|c|c|}
\hline Study & Year of publication & Region & Recruitment years & Patients (n) & Study design & IHE quality scoring \\
\hline Aso & 2016 & Japan & 2010-2013 & 4,658 & $\begin{array}{l}\text { Retrospective, } \\
\text { database }\end{array}$ & $\mathrm{H}$ \\
\hline Aubin & 2017 & Germany & 2011-2015 & 160 & $\begin{array}{l}\text { Retrospective, } \\
\text { database }\end{array}$ & $\mathrm{H}$ \\
\hline Bakhtiary & 2008 & Germany & 2003-2006 & 45 & Retrospective & M \\
\hline Bougouin & 2017 & France & 2011-2015 & 52 & Retrospective & $\mathrm{H}$ \\
\hline Boulate & 2013 & France & 2004-2012 & 55 & Retrospective & M \\
\hline Burrell & 2015 & Australia & $2007-2013$ & 104 & $\begin{array}{l}\text { Retrospective, } \\
\text { observational, case } \\
\text { series }\end{array}$ & $\mathrm{H}$ \\
\hline Burrell & 2018 & Australia & $2007-2013$ & 144 & $\begin{array}{l}\text { Retrospective, } \\
\text { observational }\end{array}$ & $\mathrm{H}$ \\
\hline Cakici & 2017 & Turkey & 2010-2015 & 148 & $\begin{array}{l}\text { Retrospective, case } \\
\text { series }\end{array}$ & $\mathrm{H}$ \\
\hline de Chambrun & 2016 & France & 2007-2015 & 94 & Retrospective & $\mathrm{H}$ \\
\hline den Uil & 2017 & Netherlands & 2004-2016 & 132 & $\begin{array}{l}\text { Retrospective, } \\
\text { database }\end{array}$ & $\mathrm{H}$ \\
\hline Distelmaier & 2016 & Austria & 2003-2014 & 385 & Prospective & M \\
\hline Elsharkawy & 2010 & USA & 1995-2006 & 233 & Retrospective & M \\
\hline Flecher & 2014 & France & 2005-2013 & 325 & Retrospective & $\mathrm{H}$ \\
\hline Hei & 2011 & China & 2004-2009 & 68 & Retrospective & M \\
\hline Hsu & 2010 & Taiwan & 2002-2006 & 51 & Retrospective & $\mathrm{H}$ \\
\hline Kara & 2016 & Netherlands & 2014-2015 & 24 & Prospective & M \\
\hline Karatolios & 2016 & Germany & 2013-2015 & 17 & Retrospective & M \\
\hline Kim & 2012 & Korea & 2006-2010 & 27 & Retrospective & M \\
\hline Kuroki & 2016 & Japan & 2005-2014 & 217 & Retrospective & $\mathrm{H}$ \\
\hline Lee & 2012 & Korea & 2005-2010 & 118 & Retrospective & M \\
\hline Lee & 2017 & Korea & 2010-2014 & 135 & $\begin{array}{l}\text { Retrospective, } \\
\text { observational }\end{array}$ & M \\
\hline Liden & 2009 & Sweden & 2000-2007 & 33 & Retrospective & M \\
\hline Loforte & 2014 & Italy & 2006-2012 & 228 & $\begin{array}{l}\text { Retrospective, } \\
\text { multi-center }\end{array}$ & M \\
\hline Loforte & 2012 & Italy & 2007-2011 & 73 & $\begin{array}{l}\text { Retrospective, } \\
\text { single-center }\end{array}$ & M \\
\hline Loforte & 2015 & Italy & 2004-2012 & 119 & $\begin{array}{l}\text { Retrospective, } \\
\text { single-center }\end{array}$ & M \\
\hline Lorusso & 2017 & USA & $1992-2015$ & 4,673 & Retrospective & M \\
\hline Luo & 2009 & China & 2005-2008 & 45 & Prospective & $\mathrm{H}$ \\
\hline Muehrcke & 1996 & USA & 1992-1994 & 23 & Retrospective & M \\
\hline Muller & 2016 & France & 2008-2013 & 138 & $\begin{array}{l}\text { Retrospective, } \\
\text { multi-center }\end{array}$ & $\mathrm{H}$ \\
\hline Muisal & 2016 & Poland & 2009-2015 & 29 & Retrospective & M \\
\hline Ranney & 2017 & USA & 2009-2015 & 131 & Retrospective & $\mathrm{H}$ \\
\hline Russo & 2010 & Italy & 1988-2005 & 15 & Retrospective & M \\
\hline Salna & 2018 & USA & 2007-2016 & 192 & Retrospective & $\mathrm{H}$ \\
\hline Saxena & 2015 & USA & 2003-2013 & 45 & Retrospective & $M$ \\
\hline Schmidt & 2015 & USA & 2003-2013 & 3,846 & Retrospective & $M$ \\
\hline Schopka & 2015 & Germany & 2007-2014 & 68 & Retrospective & $\mathrm{H}$ \\
\hline Sharma & 2015 & Netherlands & 2007-2012 & 66 & Retrospective & M \\
\hline Takayama & 2015 & USA & 2007-2013 & 101 & Retrospective & $\mathrm{H}$ \\
\hline Takayama & 2013 & USA & 2007-2012 & 90 & Retrospective & $\mathrm{H}$ \\
\hline Tsai & 2017 & Taiwan & 2002-2011 & 105 & Retrospective & $\mathrm{H}$ \\
\hline Wang & 2013 & China & 2004-2011 & 87 & Retrospective & M \\
\hline Willms & 1997 & USA & 1986-1995 & 81 & Retrospective & $M$ \\
\hline Yeh & 2018 & Taiwan & 2009-2012 & 99 & Retrospective & M \\
\hline Zhong & 2017 & China & 2009-2016 & 36 & Retrospective & M \\
\hline
\end{tabular}


Table S2 Study characteristics

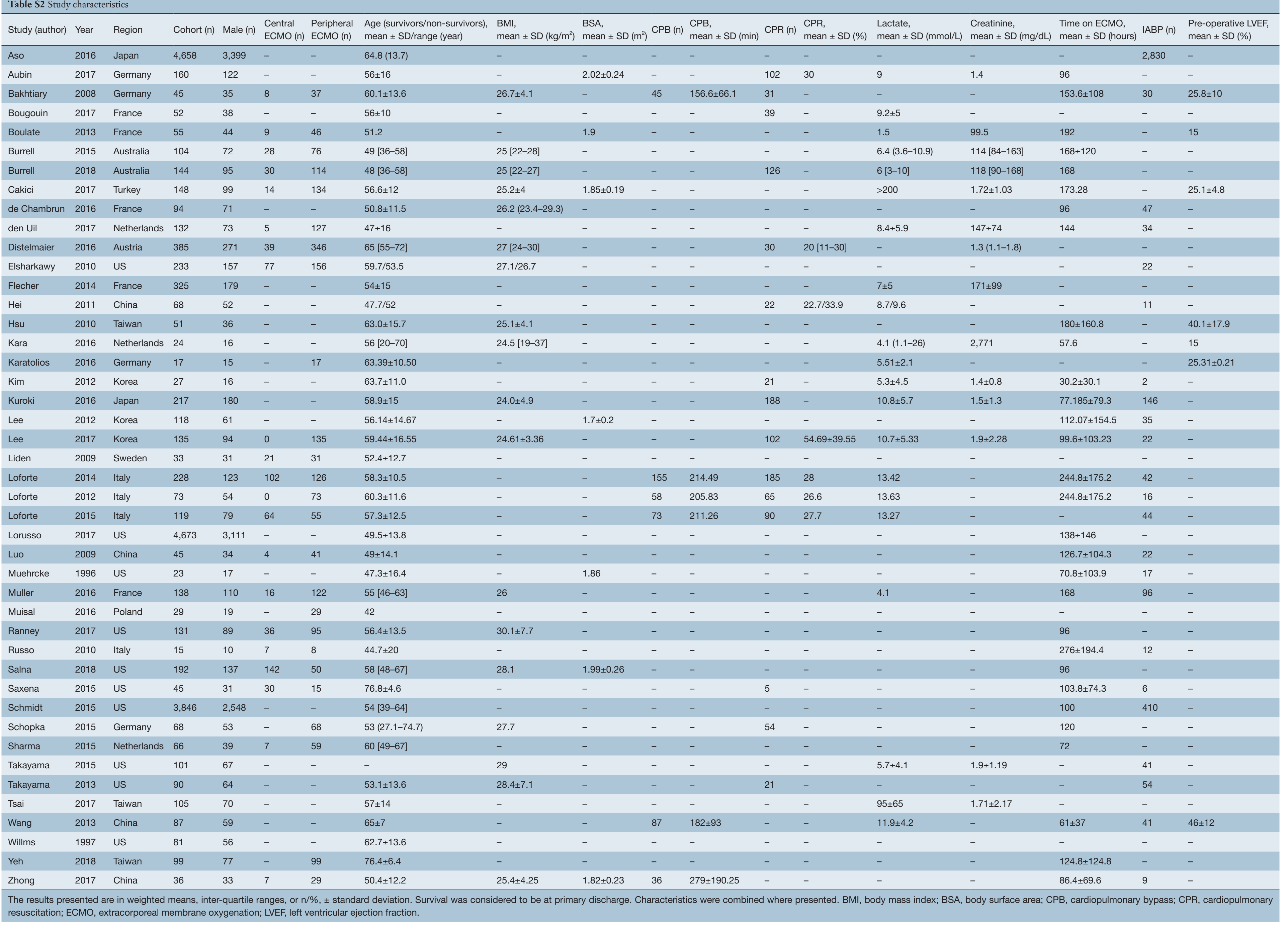




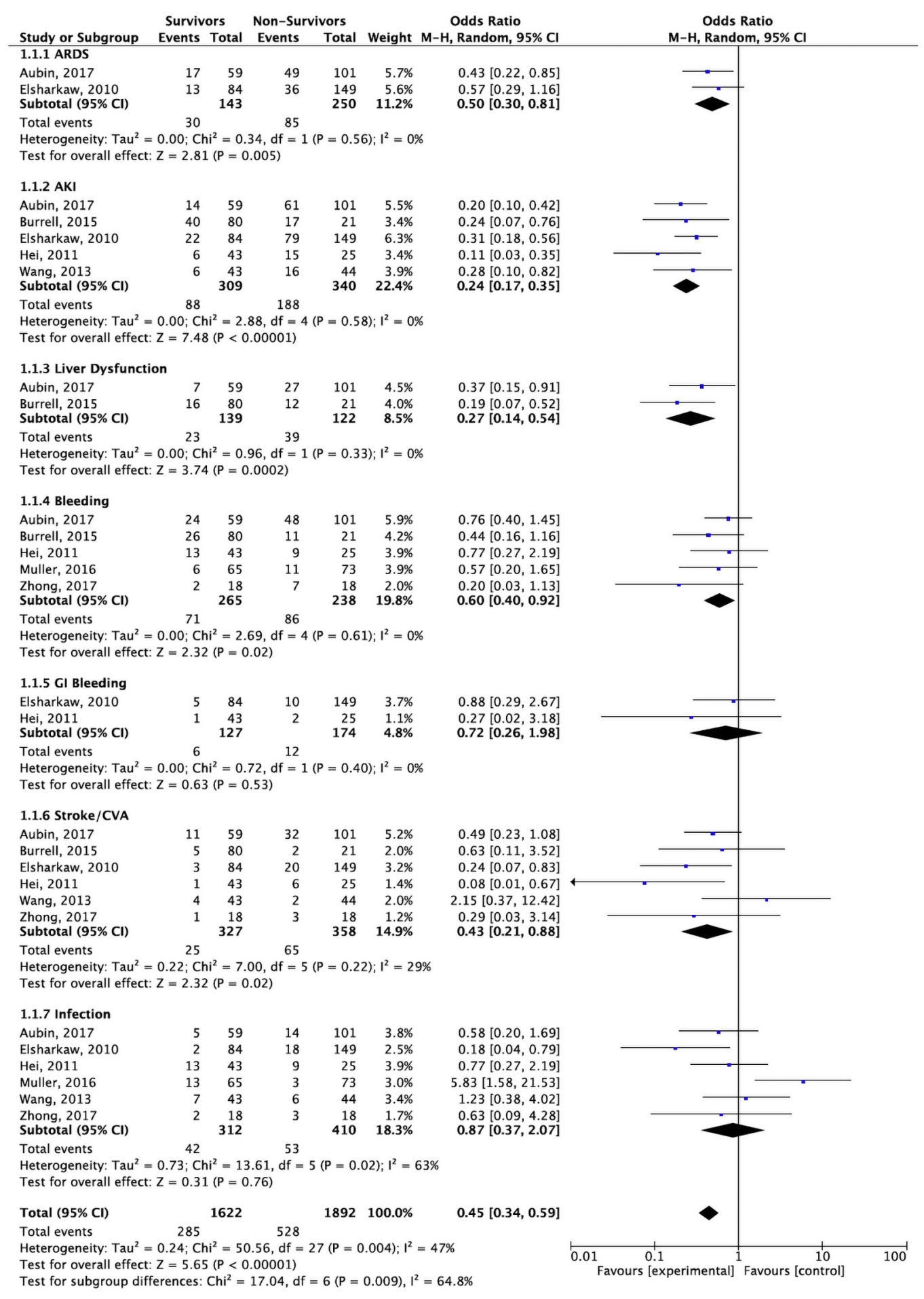

Figure S2 Forest plot analysis: in-hospital complications. Forest plot analysis illustrating outcomes; survivors (i.e., experimental) compared to non-survivors (i.e., control). Note: survivors were less likely to have infection in this analysis, but the result is not statistically significant. 